\title{
A new atractid nematode, Atractis vidali sp. n. (Nematoda: Atractidae), from cichlid fishes in southern Mexico
}

\author{
David González-Solís ${ }^{1,2}$ and František Moravec ${ }^{2}$
}

${ }^{1}$ Laboratory of Parasitology, Centre for Research and Advanced Studies of the National Polytechnic Institute (CINVESTAVIPN), Mérida Unit, Antigua Carretera a Progreso Km. 6, “Cordemex”, C.P. 97310, A.P. 73, Mérida, Yucatán, Mexico;

${ }^{2}$ Institute of Parasitology, Academy of Sciences of the Czech Republic, Branišovská 31, 370 05, České Budějovice, Czech Republic

Key words: parasitic nematode, Atractis vidali, Atractidae, freshwater fishes, Cichlasoma, Vieja, Mexico

\begin{abstract}
A new nematode species, Atractis vidali sp. n., is described from the intestine of cichlid fishes, Vieja intermedia (Günther) (type host) and Cichlasoma pearsei (Hubbs), from specimens collected in three localities in the Mexican states of Campeche (Santa Gertrudis Creek) and Chiapas (Cedros and Lacanjá Rivers). It differs from the only other atractid species reported in fishes of Mexico, Atractis bravoae, mainly in possessing two very unequal spicules. In contrast to the 10 species parasitising amphibians and reptiles in America, the new species has a longer body, spicules and a gubernaculum, and a different distribution of the caudal papillae. This is the second species of the genus Atractis recorded from freshwater fishes.
\end{abstract}

The cosmocercoid family Atractidae Railliet, 1917 is a remarkable group of nematodes including morphologically diverse species characterised by unique features of their life cycle. These parasites are ovoviviparous and their third-stage larvae develop within the uterus of the female; these are freed in the digestive tract of the host, where they complete the life cycle without passing out into the external environment (Petter 1966). Of the 19 genera of this family, 10 are parasites of reptiles and amphibians, whereas 6 genera occur in mammals. Only three genera, Atractis Dujardin, 1845, Klossinemella Costa, 1961 and Rondonia Travassos, 1920 have species parasitising freshwater fishes.

Helminthological examinations of two species of cichlids, collected from three localities in southern Mexico, revealed the presence of numerous nematodes occurring in the intestine of the fishes studied. A detailed examination of these parasites showed that they represented a new species of Atractis, which is described herein.

\section{MATERIALS AND METHODS}

A total of 15 fishes from the localities of the Lacanjá River [3 specimens of Vieja intermedia (Günther)], the Santa Gertrudis Creek [7 Cichlasoma pearsei (Hubbs)] and the Cedros River ( $2 \mathrm{~V}$. intermedia and $3 \mathrm{C}$. pearsei) in the Mexican states of Chiapas and Campeche, were examined for the presence of parasitic nematodes. Fishes were collected by using throw nets or by angling. The specimens were dissected immediately after their capture. A standard helminthological procedure was used; all nematodes were washed in physiological saline, fixed in hot $4 \%$ formaldehyde and stored in $70 \%$ ethanol. For light microscopy examination, nematodes were cleared with increasing concentrations of glycerine in water $(1: 10,1: 5,1: 2)$. For scanning electron microscopy (SEM) studies, specimens were fixed in $4 \%$ formaldehyde, postfixed in $1 \%$ osmium tetroxide, dehydrated through an ethanol series and acetone, and then subjected to critical-point drying. The specimens were coated with gold and examined with a JEOL JSM-6300 scanning electron microscope at an accelerating voltage of $15 \mathrm{kV}$. Drawings were made with the aid of an Aristoplan microscope drawing attachment. All measurements are given in millimetres, unless otherwise stated. The scientific names of fishes are according to Froese and Pauly (2001).

\section{RESULTS}

Family A t r a c t i d a e Railliet, 1917

\section{Atractis vidali sp. n.}

Figs. 1, 2

Description: Medium-sized nematodes, cuticle smooth. Head end rounded. Oral opening triangular, surrounded by 6 ridges radiating from mouth margin. Mouth surrounded by three lips, mouth papillae small, arranged in two circlets, inner circlet with 4 rod-like papillae, outer circlet with 4 spherical papillae; 2 elongate lateral amphids present. Oesophagus consisting of dilated oesophageal corpus, isthmus and valved bulb; anterior end of oesophagus triradiate, forming short pharynx. Nerve ring slightly posterior to posterior end of oesophageal corpus; excretory pore posterior to oesophagus. Deirids small, somewhat anterior to nerve ring level. Tail slender, sharply pointed.

Male (based on 11 specimens, measurements of holotype in parentheses): Length of body 5.559-6.791 (6.791), maximum width $0.246-0.425(0.425)$. Pharynx 0.017-0.023 (0.017) long and 0.064-0.067 (0.067) wide. Length of entire oesophagus $0.790-0.841$ (0.833). 


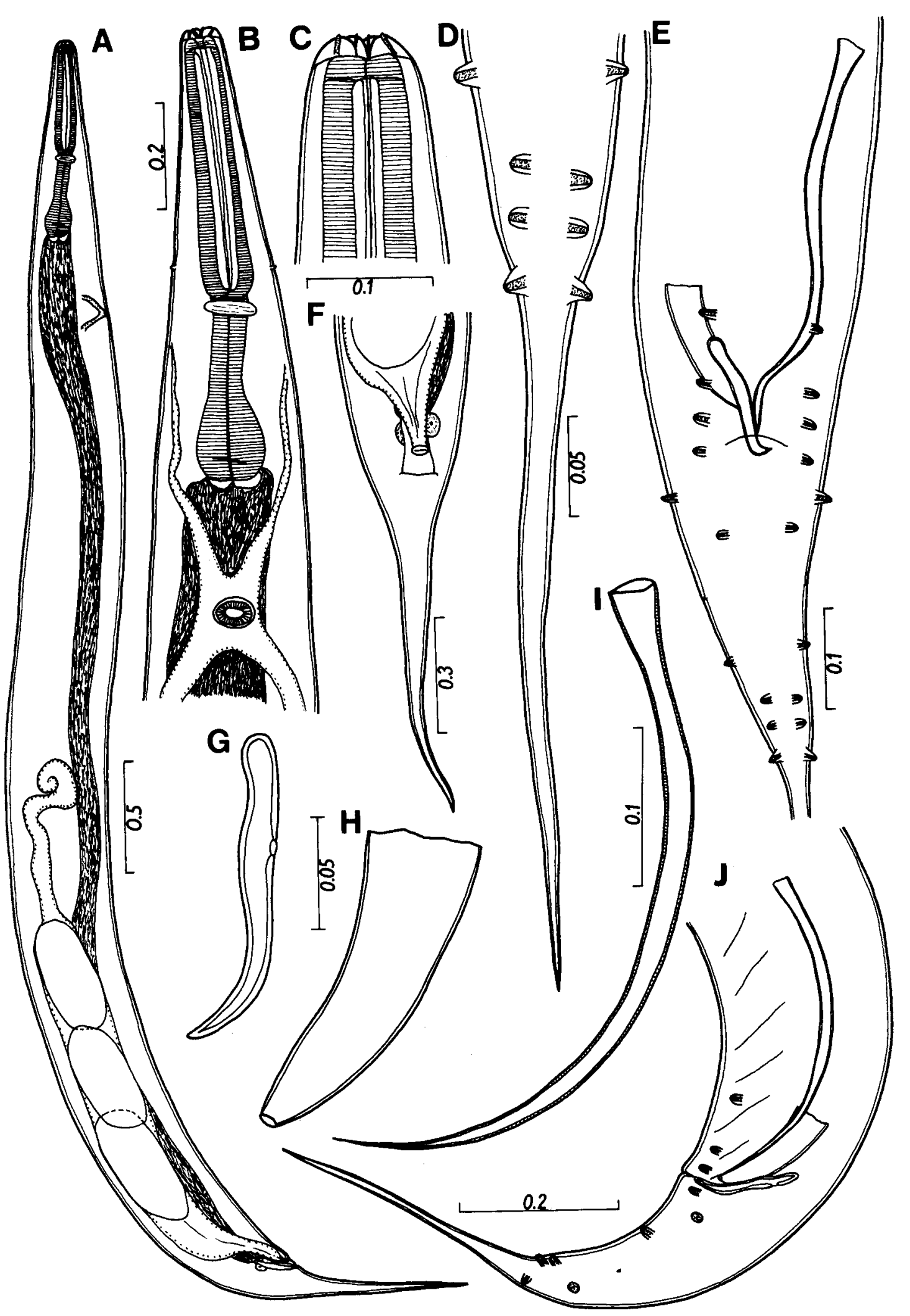

Fig. 1. Atractis vidali sp. n. A - female, general view; $\mathbf{B}$ - anterior end of body, ventral view; $\mathbf{C}$ - cephalic end; $\mathbf{D}$ - posterior part of male tail, ventral view; $\mathbf{E}, \mathbf{J}$ - posterior end of male, ventral and lateral views; $\mathbf{F}$ - posterior end of female, ventral view; $\mathbf{G}$ - gubernaculum; $\mathbf{H}$ - small spicule; $\mathbf{I}$ - large spicule. Scale bars in $\mathrm{mm}$. 

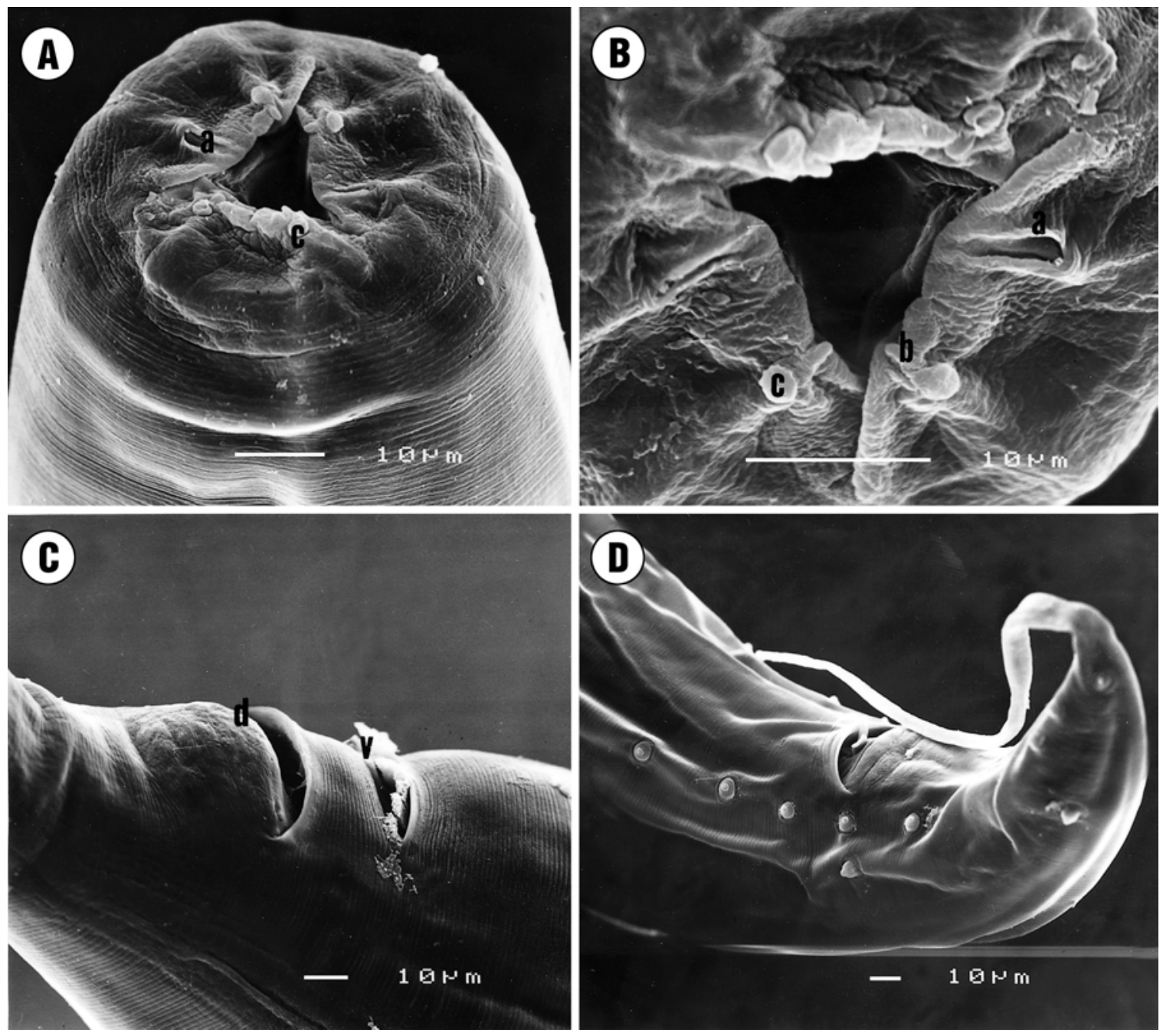

Fig. 2. Atractis vidali sp. n., scanning electron micrographs. A - cephalic end, subapical view; $\mathbf{B}$ - detail of mouth opening; $\mathbf{C}-$ region of vulva and anus; $\mathbf{D}$ - posterior end of male, subventral view. a - amphid; b - cephalic papilla of inner circle; c - cephalic papilla of outer circle; $d$ - anus; $v$ - vulva.

Anterior part of oesophagus (corpus) $0.459-0.493$ (0.467) long. Posterior part of oesophagus (isthmus and bulb) $0.323-0.365$ (0.365) long. Nerve ring, excretory pore, and deirids $0.501-0.552$ (0.518), 0.969-1.232 (1.232), and 0.399-0.484 (0.454), respectively, from anterior extremity. Ten pairs of caudal papillae: 3 preanal, 1 adanal and 6 postanal; all preanal and adanal pairs subventral; second, fourth and fifth postanal pairs subventral; first, third and sixth pairs lateral. Spicules unequal and dissimilar, well sclerotised. Large spicule (left) $0.413-0.487$ (0.477) long, with proximal end slightly expanded and distal end pointed. Small spicule (right) 0.144-0.158 (0.158) long, funnel-shaped, with proximal end widely expanded and distal end narrowed. Gubernaculum 0.144-0.151 (0.148) long, well sclerotised, with proximal end somewhat broader than distal end, the latter ventrally curved and with rounded tip. Tail conical, 0.663-0.807 (0.705) long, slender, narrowed posteriorly, ending in a sharp tip.
Female (based on 16 gravid specimens, measurements of allotype in parentheses): Length of body 6.094-8.389 (8.389), maximum width 0.314-0.569 (0.569). Pharynx 0.017-0.023 (0.023) long and 0.064$0.074(0.074)$ wide. Length of entire oesophagus 0.799 0.913 (0.888). Anterior part of oesophagus (corpus) 0.467-0.531 (0.501) long. Posterior part of oesophagus (isthmus and bulb) $0.331-0.387$ (0.387) long. Nerve ring, excretory pore, and deirids $0.510-0.561$ (0.548), 1.130-1.394 (1.394), and 0.420-0.494 (0.474), respectively, from anterior end of body. Tail conical, $0.833-$ 1.011 (1.011) long, slender, sharply pointed. Vulva at short distance anterior to anal opening, 0.884-1.071 (1.071) from posterior extremity. Vagina short, directed anteriorly. Monodelphic. Uterus containing fully developed larvae, 1.881-2.100 long and 0.091-0.118 wide, and a few developing eggs, 0.561-0.790 long and 0.238-0.331 wide. 
$\mathrm{T}$ y $\mathrm{p}$ e $\mathrm{h}$ o s t : Vieja intermedia (Günther) (Cichlidae, Perciformes).

Site of infection: Intestine.

T y p e 1 o c a 1 i t y : Lacanjá River $\left(16^{\circ} 46^{\prime} 21^{\prime \prime} \mathrm{N}\right.$, $91^{\circ} 04 ' 21^{\prime \prime} \mathrm{W}$ ), Chiapas, Mexico (holotype, allotype and paratypes collected on 21 May 1998).

A n o th e r hos t: Cichlasoma pearsei (Hubbs) (Cichlidae, Perciformes).

O t h e r 1 o c a 1 i t i e s : Santa Gertrudis Creek $\left(18^{\circ} 26^{\prime} 51^{\prime \prime N}\right.$, 9149’38”W), Campeche (8 April 1998), Cedros River $\left(16^{\circ} 45^{\prime} 21^{\prime \prime} \mathrm{N}, 91^{\circ} 09^{\prime} 30^{\prime \prime} \mathrm{W}\right)$, Chiapas, Mexico (21 May 1998).

P r e va le n c e a n d i n t e n s i t y : Lacanjá: $V$. intermedia: 1 fish infected / 3 fish examined, 211 nematodes. Santa Gertrudis: C. pearsei: 3/7, 55-148. Cedros: V. intermedia: $1 / 2 ; 20 ;$ C. pearsei: $2 / 3,80-1,854$.

Deposition of s pecimens: Holotype and allotype in the National Helminthological Collection, National Autonomous University of Mexico (No. 4443), paratypes in the Helminthological Collection CINVESTAV-IPN, Mérida (Cat. No. 0433) and in the Institute of Parasitology, Academy of Sciences of the Czech Republic, České Budějovice (No. N-784).

E t y m o lo g y : The specific name "vidali" is in honour of Dr. Victor M. Vidal Martínez, head of the Laboratory of Parasitology in the CINVESTAV-IPN, Mérida.

\section{DISCUSSION}

The general morphology of these nematodes, particularly the triangular mouth opening, surrounded by six anteriorly protruding lip-like elevations, and the presence of an oesophagus consisting of a dilated, triradiate oesophageal corpus, forming a short pharynx, isthmus and a valved bulb, shows clearly that they belong to the genus Atractis. This genus includes many species parasitic in turtles and lizards, and one species is known from toads (Skryabin et al. 1964, Baker 1987). The only species known from fishes is A. bravoae (Osorio-Sarabia, 1984), originally reported as Laurotravassoxyuris bravoae from the cichlid Cichlasoma istlanum (Jordan et Snyder) and the atherinid
Atherinella balsana (Meek) (reported as Melaniris balsanus) from Michoacán, Mexico (Osorio-Sarabia 1984) and later transferred to Atractis by Moravec (2000). Members of the genus Atractis possess spicules of a markedly different length with either similar or dissimilar shapes, with the exception of $A$. perarmata Linstow, 1910 and A. bravoae (Osorio-Sarabia, 1984), which have spicules of an approximately equal length.

In America, 10 species of this genus have been reported to date, of which only $A$. impura Caballero, 1944 shows similar characteristics of its spicules as those of $A$. vidali. However, A. vidali differs from it mainly in having distinctly larger body measurements, longer spicules and a gubernaculum, and a dissimilar distribution of the caudal papillae. There are four congeneric species, A. dactyluris (Rudolphi, 1891), $A$. africana Ortlepp, 1933, A. fasciolata Gendre, 1909 and A. ortleppi Thapar, 1925 reported from amphibians and reptiles in different countries that have similar spicules and a distribution of caudal papillae as $A$. vidali. However, they have smaller body measurements, a short tail, and their excretory pore is located more anteriorly. By its morphology, $A$. vidali is also very close to $A$. chabaudi Petter, 1966, a species described from the tortoise Pyxis arachnoides Bell in Madagascar. The new species differs from it in the greater lengths of the body, spicules and the gubernaculum, and somewhat in the distribution of caudal papillae. Of the species of this genus, only $A$. bravoae was previously reported from fishes. Consequently, A. vidali is the second Atractis species known to parasitise fishes. It may well be that $A$. vidali is specific to cichlid fishes.

Acknowledgements. The authors wish to thank the staff of the Laboratory of Parasitology of the Centre for Research and Advanced Studies of the National Polytechnic Institute in Mérida for collecting and examining fishes and the staff of the Laboratory of Electron Microscopy of the Institute of Parasitology, ASCR, in České Budějovice for their technical assistance. This work was partly supported by the grant No. A6022901 from the Grant Agency of the Academy of Sciences of the Czech Republic.

\section{REFERENCES}

BAKER M.R. 1987: Synopsis of the Nematoda Parasitic in Amphibians and Reptiles. Occasional Papers in Biology, Memorial University of Newfoundland, Newfoundland, Canada, No. 11, 325 pp.

FROESE R., PAULY D. (Eds.) 2001: FishBase. World Wide Web electronic publication. www.fishbase.org, 02 January 2002.

MORAVEC F. 2000: Systematic status of Laurotravassoxyuris bravoae Osorio-Sarabia, 1984 (Nematoda: Pharyngodonidae) [= Atractis bravoae (Osorio-Sarabia, 1984) n. comb.: Cosmocercidae]. Syst. Parasitol. 46: 117-122.
OSORIO-SARABIA D. 1984: Descripción de una especie nueva del género Laurotravassoxyuris Vigueras, 1938 (Nematoda: Syphaciidae) en peces de agua dulce de México. An. Inst. Biol. Univ. Nac. Autón. Méx., Ser. Zool., 54: 23-33.

PETTER A.-J. 1966: Équilibre des espèces dans les populations de nématodes parasites du colon des tortues terrestres. Mem. Mus. Natl. Hist. Nat., Zool., 39: 1-245.

SKRYABIN K.I., SCHIKHOBALOVA N.P., LAGODOVSKAYA E.A. 1964: Oxyurata of Animals and Man, Part 3. Osnovy Nematodologii 13. Nauka, Moscow, 468 pp. (In Russian.)

Accepted 30 January 2002 